\title{
Intra-articular temperatures of the knee in sports - An in-vivo study of jogging and alpine skiing
} Christoph Becher*1, Jan Springer ${ }^{2}$, Sven Feil ${ }^{2}$, Guiliano Cerulli ${ }^{3}$ and Hans H Paessler²

\author{
Address: ${ }^{1}$ Department of Orthopaedic Surgery, Phillips University, Marburg, Germany, ${ }^{2}$ Center for Knee \& Foot Surgery/Sports Trauma, ATOS \\ Clinic, Heidelberg, Germany and 3 "Lets people move" Institute, University of Perugia, Perugia, Italy \\ Email: Christoph Becher* - becher.chris@web.de; Jan Springer - science@atos.de; Sven Feil - science@atos.de; \\ Guiliano Cerulli - letpeoplemove@tin.it; Hans H Paessler - hans.paessler@atos.de \\ * Corresponding author
}

Published: II April 2008

BMC Musculoskeletal Disorders 2008, 9:46 doi:10.1 186/147/-2474-9-46

This article is available from: http://www.biomedcentral.com/147I-2474/9/46

(C) 2008 Becher et al; licensee BioMed Central Ltd.

This is an Open Access article distributed under the terms of the Creative Commons Attribution License (http://creativecommons.org/licenses/by/2.0), which permits unrestricted use, distribution, and reproduction in any medium, provided the original work is properly cited.
Received: 5 November 2007

Accepted: II April 2008

\begin{abstract}
Background: Up to date, no information exists about the intra-articular temperature changes of the knee related to activity and ambient temperature.

Methods: In 6 healthy males, a probe for intra-articular measurement was inserted into the notch of the right knee. Each subject was jogging on a treadmill in a closed room at $19^{\circ} \mathrm{C}$ room temperature and skiing in a ski resort at $-3^{\circ} \mathrm{C}$ outside temperature for 60 minutes. In both conditions, temperatures were measured every fifteen minutes intra-articulary and at the skin surface of the knee. A possible influence on joint function and laxity was evaluated before and after activity. Statistical analysis of intra-articular and skin temperatures was done using nonparametric Wilcoxon's sign rank sum test and Mann-Whitney's-U-Test.

Results: Median intra-articular temperatures increased from $31.4^{\circ} \mathrm{C}$ before activity by $2.1^{\circ} \mathrm{C}, 4^{\circ} \mathrm{C}$, $5.8^{\circ} \mathrm{C}$ and $6.1^{\circ} \mathrm{C}$ after $15,30,45$ and 60 min of jogging (all $\mathrm{P} \leq 0.05$ ). Median intra-articular temperatures dropped from $32.2^{\circ} \mathrm{C}$ before activity by $0.5^{\circ} \mathrm{C}, 1.9^{\circ} \mathrm{C}, 3.6^{\circ} \mathrm{C}$ and $1.1^{\circ} \mathrm{C}$ after 15,30 , 45 and 60 min of skiing (all n.s.). After 60 minutes of skiing (jogging), the median intra-articular temperature was $19.6 \%(8.7 \%)$ higher than the skin surface temperature at the knee. Joint function and laxity appeared not to be different before and after activity within both groups.
\end{abstract}

Conclusion: This study demonstrates different changes of intra-articular and skin temperatures during sports in jogging and alpine skiing and suggests that changes are related to activity and ambient temperature.

\section{Background}

Intra-articular temperatures were well investigated in recent years. The first analysis of intra-articular temperatures in humans was published in 1949 by Horvath and Hollander based on the thought that arthritic joints were not only warm to the touch but had a higher intra-articu- lar temperature as compared with unaffected joints [1]. A statistically significant decline in intraarticular knee temperature with the application of ice and compression to the skin was first documented by Martin et al. in 2001 [2]. Several authors have investigated the influence of application of cold, heat or pathological conditions such as syn- 
ovitis on the change of the physiological intra-articular temperature of the knee [3-8]. Beneficial effects of cooling of joints after acute injury or in the postoperative period were reported with shorter hospitalization, less pain with fewer need for analgesics and less swelling [9-13]. Improved range of motion progression and exercise tolerance are other constituted advantages [9-14]. However, cold or heat to a joint is of concern to have negative influence on muscle performance and increased risk of injury and therefore discussed controversial [15-21].

To our best knowledge, no reports exist about the changes of the intra-articular temperatures and skin surface temperatures of the knee during sports activity. The objectives of the present study are to evaluate differences of intraarticular and skin surface temperatures related to activity and ambient temperature. Furthermore, a possible impact on joint function and laxity is examined.

\section{Methods}

6 healthy males were included in the study after approval by the institutional review board and informed consent. The average age of the participants was 29.3 years (range: 27 - 32 years). The average Body Mass Index (BMI) was 23.61 (range: $22.78-25.25$ ). On examination, all participants had full, pain-free range of motion, stable ligaments and no effusion or tenderness to palpation.

For preparation of the implantation procedure, the subject was sitting with the knee flexed to $90^{\circ}$. The probe for the intra-articular measurement was inserted intra-articulary under local anaesthesia (Bupivacain $0.5 \%$ ) into the notch under sterile conditions through an 18-gauge needle introduced to the medial aspect of the right knee (Fig. 1). All implantations were done by the senior investigator (HHP). The introduced device was a flexible Teflon coated thermocouple probe (Model IT-18, Physitemp Instruments Inc, New Jersey, U.S.A.; max. temp. $150^{\circ}$, time constant 0.1 sec., sensor lead $0.25^{\prime \prime}$ dia, length 3 feet). A second and third thermocouple probe (Model SST-1, Physitemp Instruments Inc, Clifton, New Jersey, U.S.A; 10 Kt. Gold sensor disc, not isolated, max. temp. $90^{\circ}$, time constant $0.15 \mathrm{sec}$.) was placed on the skin $2 \mathrm{~cm}$ proximal of the patella and fixed with adhesive tape. The temperature was recorded with the TH-8 Thermalert Monitoring Thermometer (Physitemp Instruments Inc, Clifton, New Jersey, U.S.A.; accuracy of $0.1^{\circ} \mathrm{C} \pm 0.2 \%$, stability \pm $0.1^{\circ} \mathrm{C}$ ). These devices were successfully used by other authors in the same application [8].

\section{Study protocol jogging}

All subjects wore common sport shorts that ended above the knees for performing the run. Each participant was jogging on a treadmill at a speed of $6.5 \mathrm{~km} / \mathrm{h}$ for $60 \mathrm{~min}$ -

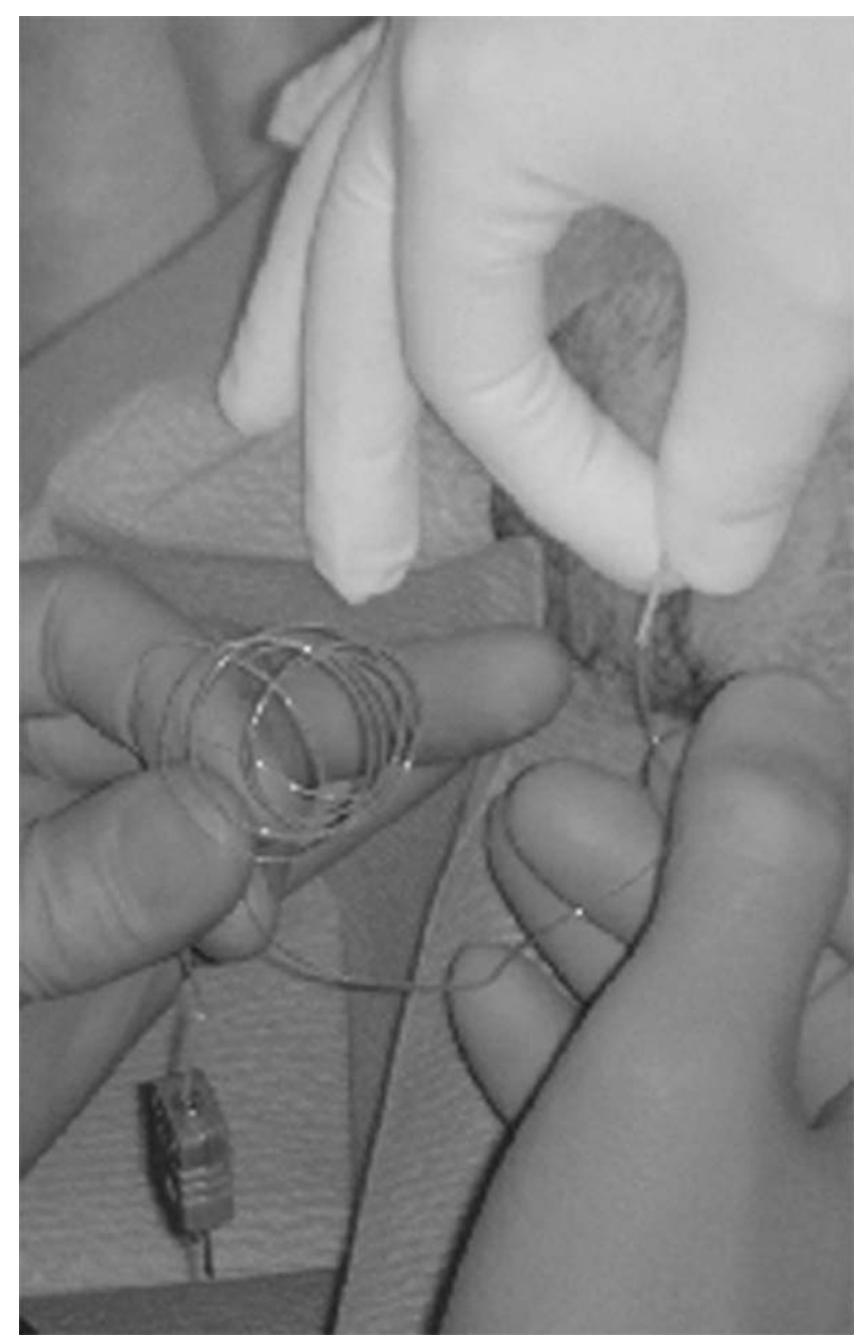

Figure I

Intra-articular insertion of the probe into the notch.

utes. Every fifteen minutes, the temperature was measured intra-articulary and at the skin.

\section{Study protocol skiing}

The implantation of the probe was done in a harborage next to the slope. Each participant used skiing suits of the same style and material (Shell: 100\% Nylon; Trim: 100\% Polyester; Lining: $100 \%$ Nylon) without skiing underwear. The slope was rated at an easy degree of difficulty with a length of 800 meter. Ascent was provided by a chair lift. The participants were requested to ride on a basic level to provide comparable activity levels. Every fifteen minutes, the temperature was measured intra-articulacy and at the skin. For that purpose, the skiing suit had to be released in a manner to set the probe free. Measurements were done in outside conditions next to the entrance of 
the chair lift and were performed to the exact point in time.

The outside temperature in the laboratory where the trial was done was $19^{\circ} \mathrm{C}$; the outside temperature at the skiing resort was $-3^{\circ} \mathrm{C}$ at the entrance of the chair lift. The outside temperatures did not change during the trial. Jogging and skiing was each started around 10 o'clock am. Between the jogging and skiing activity, the subjects had one day of rest for recovery.

Three different tests were used to evaluate joint function and laxity (neuromuscular function, intermuscular coordination, strength, proprioception and anterior-posterior stability). Every test was performed before and after the implantation of the probe as well as after the activity. The tests were performed in the same manner under equal conditions in the lab and in the harborage next to the slope. The mean value of three independent measurements was taken for data analysis. Every subject underwent three repetitions of every testing modality prior to the trial to get used to the tests. For evaluation of passive anterior knee joint stability, a Lachman-test was performed using the KT 2000 knee arthrometer (Medmetrics, San Diego, Calif., U.S.A). Strength and intermuscular coordination were investigated by a single leg hop test. This test was used by many researchers to study knee function in ACL-deficient persons particularly because hopping is more challenging than walking or jogging and is thought by some to more closely represent the demand of high level sports $[22,23]$. The joint position sense was evaluated using a passive angle reproduction test using a standard goniometer. Patient eyes were closed in order to eliminate visual stimuli.

For statistical analysis descriptive statistics were summarized with medians and ranges. Complete data sets were available for $2 \times 6$ persons. All data were tested for deviation from the normal distribution within the groups using Box-and-Whisker-Plots. Temperature changes over time and differences within one group were assessed using a paired Wilcoxon sign rank sum test. A Mann-Whitney-UTest was used to assess differences between groups. These non-parametric two-tailed tests are not based on assumptions about the normal distribution. The Box-andWhisker Plot displays the first and third quartiles as the ends of the box, the maximum and minimum as the whiskers and the median as a vertical bar in the interior of each box. Extreme values did not appear. All tests were two-sided and a p-value $\leq 0.05$ was considered significant. Descriptive mean and 95\%-confidence intervals were calculated for all variables of joint function. Data analysis was performed with SPSS for Windows 12.0 (SPSS inc. Chicago, Illinois, USA).

\section{Results}

\section{Temperature measurements}

The median initial intra-articular temperatures (Fig. 2) of the jogging group $\left(31.4^{\circ} \mathrm{C}, \mathrm{min} /\right.$ max-range $29.7^{\circ} \mathrm{C} /$ $34.3^{\circ} \mathrm{C}$ ) and the skiing group $\left(32.2^{\circ} \mathrm{C}, \mathrm{min} /\right.$ max-range $\left.29.7^{\circ} \mathrm{C} / 32.3^{\circ} \mathrm{C}\right)$ revealed no statistical significant difference $(\mathrm{p}=0.377)$. Compared to the baseline temperature values, median intra-articular temperatures in the jogging group increased by $2.1^{\circ} \mathrm{C}, 4^{\circ} \mathrm{C}, 5.8^{\circ} \mathrm{C}$ and by $6.1^{\circ} \mathrm{C}$ after $15 \mathrm{~min}\left(33.5^{\circ} \mathrm{C} ; \min / \max\right.$ range $\left.32^{\circ} \mathrm{C} / 36.5^{\circ} \mathrm{C} ; \mathrm{p}=0.05\right)$, $30 \min \left(35.4^{\circ} \mathrm{C}\right.$; $\min / \max$ range $34.3^{\circ} \mathrm{C} / 37.7^{\circ} \mathrm{C} ; \mathrm{p}<$ $0.05), 45 \mathrm{~min}\left(37.2^{\circ} \mathrm{C} ; \min / \max\right.$ range $35.7^{\circ} \mathrm{C} / 38.7^{\circ} \mathrm{C} ; \mathrm{p}$ $<0.05)$ and $60 \mathrm{~min}\left(37.5^{\circ} \mathrm{C}\right.$; $\min / \max$ range $36.1^{\circ} \mathrm{C} /$ $\left.38.8^{\circ} \mathrm{C} ; \mathrm{p}<0.05\right)$ of activity. Median intra-articular temperatures in the skiing group dropped by $0.5^{\circ} \mathrm{C}, 1.9^{\circ} \mathrm{C}$, $3.6^{\circ} \mathrm{C}$ and $1.1^{\circ} \mathrm{C}$ after $15 \mathrm{~min}\left(31.7^{\circ} \mathrm{C}\right.$; $\mathrm{min} / \mathrm{max}$ range $27.9^{\circ} \mathrm{C} / 33.9^{\circ} \mathrm{C}$; n.s. $), 30 \mathrm{~min}\left(30.3^{\circ} \mathrm{C}\right.$; $\mathrm{min} / \mathrm{max}$ range $25.2^{\circ} \mathrm{C} / 34,3^{\circ} \mathrm{C}$; n.s. $), 45 \mathrm{~min}\left(29.8^{\circ} \mathrm{C}\right.$; $\mathrm{min} / \mathrm{max}$ range $24,7^{\circ} \mathrm{C} / 34,4^{\circ} \mathrm{C}$; n.s. $)$ and $60 \min \left(31.1^{\circ} \mathrm{C}\right.$; min/max range $24.4^{\circ} \mathrm{C} / 34.5^{\circ} \mathrm{C}$; n.s.) of activity.

The skin surface temperatures at the knees (Fig. 3) revealed median increases in the jogging group from $26.6^{\circ} \mathrm{C}\left(\mathrm{min} / \mathrm{max}\right.$ range $\left.25.5^{\circ} \mathrm{C} / 28.0^{\circ} \mathrm{C}\right)$ before activity by $2.3^{\circ} \mathrm{C}, 5.1^{\circ} \mathrm{C}, 7.6^{\circ} \mathrm{C}$ and $7.9^{\circ} \mathrm{C}$ at $15 \mathrm{~min}\left(28.9^{\circ} \mathrm{C}\right.$; $\mathrm{min} / \mathrm{max}$ range $\left.27.0^{\circ} \mathrm{C} / 35.0^{\circ} \mathrm{C} ; \mathrm{p}<0.05\right), 30 \mathrm{~min}$ $\left(31.7^{\circ} \mathrm{C} ; \mathrm{min} / \max\right.$ range $\left.27.6^{\circ} \mathrm{C} / 35.6^{\circ} \mathrm{C} ; \mathrm{p}<0.05\right), 45$ $\min \left(34.2^{\circ} \mathrm{C}\right.$; $\min / \max$ range $30.7^{\circ} \mathrm{C} / 35.7^{\circ} \mathrm{C}$; $\left.\mathrm{p}<0.05\right)$ and $60 \mathrm{~min}\left(34.5^{\circ} \mathrm{C}\right.$; $\min / \max$ range $32.9^{\circ} \mathrm{C} / 36.1^{\circ} \mathrm{C}$; $\mathrm{p}<$ $0.05)$ of activity. The temperatures at the skiing group

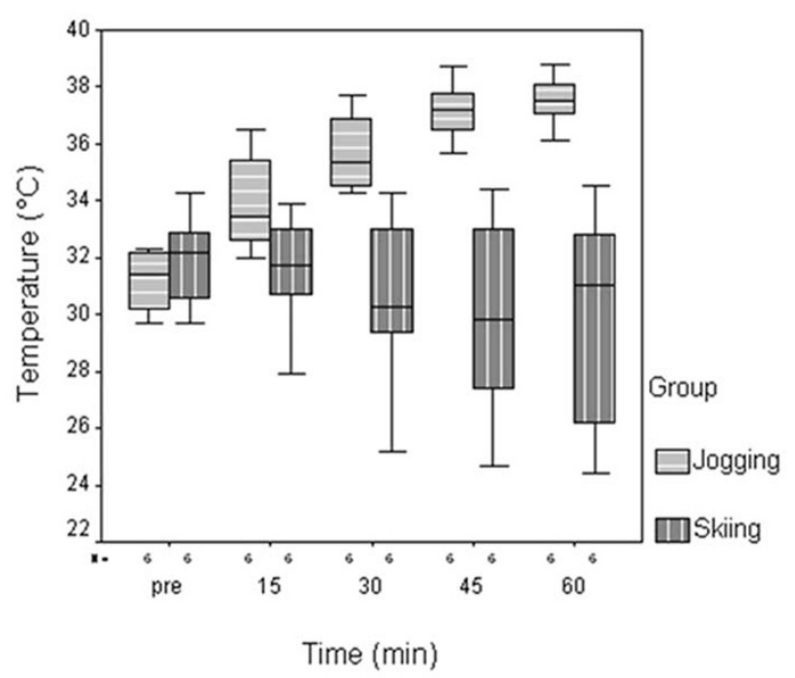

\section{Figure 2}

Intra-articular temperatures measured before and during jogging and skiing activity over one hour. Significant increase of intra-articular temperatures was measured after 15, 30, 45 and $60 \mathrm{~min}$ in the jogging group. No significant changes were observed in the skiing group. 


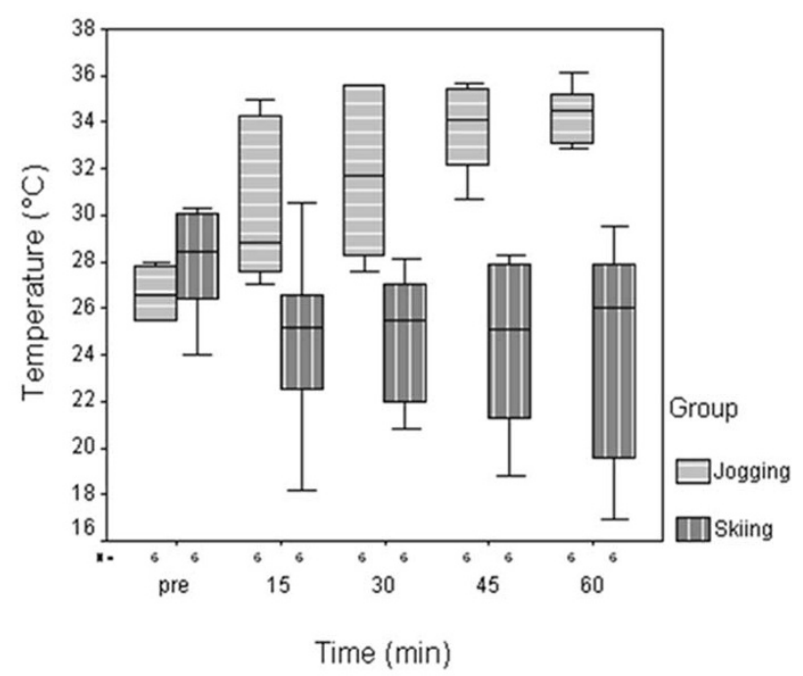

Figure 3

Skin surface temperatures at the knee measured before and during jogging and skiing activity over one hour. Significant increase of the skin surface temperatures was measured after 15, 30, 45 and $60 \mathrm{~min}$ in the jogging group. No significant changes were observed in the skiing group.

dropped from $28.5^{\circ} \mathrm{C}\left(\mathrm{min} / \mathrm{max}\right.$ range $\left.24.0^{\circ} \mathrm{C} / 30.3^{\circ} \mathrm{C}\right)$ before activity by $3.3^{\circ} \mathrm{C}, 3.0^{\circ} \mathrm{C}, 3.4^{\circ} \mathrm{C}$ and $2.5^{\circ} \mathrm{C}$ after 15 $\min \left(25.2^{\circ} \mathrm{C} ; \min / \max\right.$ range $18.2^{\circ} \mathrm{C} / 30.5^{\circ} \mathrm{C}$; n.s. $), 30$ $\min \left(25.5^{\circ} \mathrm{C} ; \min / \max\right.$ range $20.8^{\circ} \mathrm{C} / 28.1^{\circ} \mathrm{C}$; n.s. $), 45$ $\min \left(25.1^{\circ} \mathrm{C} ; \min / \max\right.$ range $\left.18.8^{\circ} \mathrm{C} / 28.3^{\circ} \mathrm{C} ; \mathrm{p}=0.05\right)$ and $60 \mathrm{~min} .\left(26.0^{\circ} \mathrm{C} ; \mathrm{min} / \mathrm{max}\right.$ range $16.9^{\circ} \mathrm{C} / 29.5^{\circ} \mathrm{C}$; n.s.) of activity.

Comparing the intra-articular with the skin knee temperature after 60 minutes of skiing (jogging), the median intra-articular temperature was $19.6 \%(8.7 \%)$ higher than the skin temperature at the knee.

\section{Joint function and laxity}

The ability to perform the single leg hop test seemed not to be decreased after activity compared to the situation before activity in both groups. However, implantation of the probe appeared to decrease the ability for hopping (Table 1). Comparing the two groups for their ability for hopping before activity revealed no obvious differences. The skiing group, however, slightly improved their median ability for hopping after the activity, whereas the joggers could not achieve the same results as prior to the trial (Table 1).

Joint laxity (Table 2) and joint position sense (Table 3) within the groups appeared not to be influenced by the implantation of the probe or the activity. Implantation of the probe, however, appeared to decrease accurate reproduction of joint angles.

\section{Discussion}

Changes of intra-articular temperatures were well investigated in the field of orthopaedic surgery to study possible beneficial mechanisms of cold application and to evaluate potential negative effects on joint homeostasis $[2,5,7,9$ 13,24-26]. However, up to date, we had no knowledge about the changes and possible effects of intra-articular temperature changes related to activity and ambient temperature.

Haimovici measured the intra-articular temperature of healthy human knees to be $32.8^{\circ} \mathrm{C}$ on average [3]. The initial temperatures in our study group were slightly lower but consistent with the findings of other investigators $[7,8]$. Although our healthy young male subjects performed knee demanding activity by alpine skiing, the median intra-articular and skin knee temperatures dropped over the testing time of 60 minutes. Thus, the cool outside temperature appeared to influence the intraarticular and skin knee temperatures. However, in contrast to studies with cooling, but without activity demand of the knee $[8,24]$, the intra-articular temperatures did not drop significantly.

In the jogging group, median intra-articular temperatures increased to $37.5^{\circ} \mathrm{C}$ after 60 min of activity, which was $8.7 \%$ higher than the median skin knee temperatures. In synovitis and inflammatory disease, the intra-articular temperature was found to be around $35^{\circ} \mathrm{C}$ to $36^{\circ} \mathrm{C}[6]$. At such temperatures, enzymatic activity (by cartilagedegrading cytokines such as IL-1 and IL-6, metalloproteinases, and other substances), may lead to cartilage damage. At intra-articular temperatures of, or slightly below $30^{\circ} \mathrm{C}$, enzymatic cartilage damage in context of synovitis will be slight $[27,28]$. Oosterveld et al. found $30^{\circ} \mathrm{C}$ to be

Table I: Single leg hop test (Median (cm) min/max-range)

\begin{tabular}{cccc}
\hline Group & Pre_implantation & Post_implantation - pre_activity & Post_activity \\
\hline Jogging & $119.5(109.7 / 150.3)$ & $99.2(91.2 / 107.4)$ & $115.7(102.7 / 157.3)$ \\
Skiing & $124.5(111.3 / 135.0)$ & $99.2(90.1 / 102.3)$ & $130.0(103.7 / 146.0)$ \\
\hline
\end{tabular}

Implantation of the probe (post_implantation - pre activity) appeared to decrease the ability to perform the single leg hop test 
Table 2: KT 2000 (Median $(\mathrm{mm}) \pm \mathrm{min} / \mathrm{max}$-range)

\begin{tabular}{cccc}
\hline Group & Pre_implantation & Post_implantation - Pre_activity & Post_activity \\
\hline Jogging & $9.0(7.0 / 10.0)$ & $8.0(7.0 / 10.0)$ & $8.5(7.0 / 10.0)$ \\
Skiing & $9.5(7.0 / 10.0)$ & $9.5(7.0 / 10.0)$ & $10.0(7.0 / 10.0)$ \\
\hline
\end{tabular}

Joint laxity within the groups appeared not to be influenced by the implantation of the probe or the activity

the threshold below which enzymatic activity and cartilage degradation were markedly reduced [29]. For cartilage damage to be caused, the temperature would need to be substantially below that threshold. Therefore he recommended to decrease intra-articular temperature in actively inflamed arthritic joints [6,30]. Increased intraarticular temperatures during sports activity in subjects with existing degenerative joint disease might lead to negative effects on the joint as found in synovitis. Therefore it raises the question if cooling during heavy demand of the knee joint should be recommended. However, temperatures around the physiological body temperature appear not to harm the articular cartilage in healthy knees. Cheng at al. evaluated the effects normal saline irrigation at different temperatures on the surface of articular cartilage in rats and found the most even surface without fibril exposure at $37^{\circ} \mathrm{C}$.

Implantation of the probe with concomitant trauma and local anaesthesia to the knee appeared to decrease the ability of hopping in our study group and seemed to decrease joint position sense. Accordingly, less performance and increased risk for knee injury must be respected in the athlete with an acutely traumatized knee.

Cold or heat to a joint is of concern to have negative influence on muscle performance and increased risk of injury and therefore discussed controversial [15-21]. Hopkins et al. found the soleus motoneuron is facilitated following a

Table 3: Joint position sense (Mean difference between predetermined and reproduced angle \pm SD)

\begin{tabular}{cccc}
\hline & $30^{\circ}$ & $60^{\circ}$ & $90^{\circ}$ \\
\hline \multicolumn{3}{c}{ Pre_implantation } \\
Jogging & $5.0^{\circ} \pm 2.89^{\circ}$ & $7.5^{\circ} \pm 3.8^{\circ}$ & $5.8^{\circ} \pm 4.5^{\circ}$ \\
Skiing & $5.0^{\circ} \pm 2.9^{\circ}$ & $6.7^{\circ} \pm 3.7^{\circ}$ & $4.2^{\circ} \pm 6.1^{\circ}$ \\
& \multicolumn{3}{c}{ Post_implantation - Pre_activity } \\
Jogging & $11.7^{\circ} \pm 6.9^{\circ}$ & $8.3^{\circ} \pm 3.7^{\circ}$ & $9.2^{\circ} \pm 7.3^{\circ}$ \\
Skiing & $7.5^{\circ} \pm 9.0^{\circ}$ & $6.67^{\circ} \pm 3.73^{\circ}$ & $8.83^{\circ} \pm 3.73^{\circ}$ \\
& & \\
Jogging & $6.7^{\circ} \pm 7.5^{\circ}$ & Post-activity \\
Skiing & $3.3^{\circ} \pm 2.4^{\circ}$ & $5.0^{\circ} \pm 4.1^{\circ} \pm 1.9^{\circ}$ & $7.5^{\circ} \pm 2.5^{\circ}$ \\
& & $7.5^{\circ} \pm 3.8^{\circ}$
\end{tabular}

Implantation of the probe (post_implantation - pre activity) appeared to decrease the joint position sense 30-minute cooling period of the ankle and supported the application of ice to the ankle prior to activity and rehabilitation [17]. Sanya and Bello reported the quadriceps strength even to be improved after cooling and therefore recommended that application of cold on muscle should be employed while rehabilitating an individual with musculoskeletal pathology or deficit particularly while training for muscle endurance, strength and restoration of muscle function [20]. Other studies support these findings reporting no influence of local cooling on proprioceptive acuity in the quadriceps muscle and isometric force variability [31,32]. The length of the cooling period appears to have an important impact whether advantageous or disadvantageous muscle function is evident. 30 minutes of cooling $\left(10^{\circ}\right)$ showed improvement of maximal isometric grip strength immediately after the application of cold but decline by the end of treatment. The application of heat $\left(40^{\circ}\right)$ leads to decline of maximum strength during the first 22 minutes. However, this trend reversed itself with improvement of strength by the end [15]. Whereas cooling was reported to make knees stiffer and lessens the knee position sense [21], cryotherapy did not impair shoulder or ankle position sense [16,18]. Hopper et al. suggested that cryotherapy is not deleterious to joint position sense and assuming normal joint integrity patients may resume exercise without increased risk of injury [18]. Our data in a limited number of subjects revealed that different skin and intra-articular temperatures appear not to decrease joint function or laxity after skiing and jogging under different ambient temperature. Interestingly, the ability for hopping among our subjects seemed to be greater after skiing than after jogging. However, if this was related to the cooler intra-articular temperatures remains uncertain and needs to be proved in a larger number of subjects.

Limitations of the study must be considered and include the following. (1) The outside conditions at the skiing resort are not applicable as in a laboratory setting and are vulnerable to changes. (2) The skiing activity of the subject could not be standardised as the activity on the treadmill with preset speed. (3) Temperature measurements were done at a given time for all subjects at the skiing resort resulting in different time frames between activity and measurement. (4) The sample size of $n=6$ was relatively small but sufficient to assess differences in intraarticular and knee skin temperatures when using non-par- 
ametric tests [33]. All data were tested for deviation from the normal distribution within the groups using Box-andWhisker Plots. No extreme values were obtained indicating a normal distribution. Possible biases were reduced by using only male subjects of comparable age and BMI. The results of joint function and laxity, however, were of concern for insufficient power and therefore not eligible for statistical analysis.

\section{Conclusion}

In conclusion, this study demonstrates different changes of intra-articular temperatures during sports in jogging and alpine skiing and suggests that changes are related to activity and ambient temperature. Further research is warranted to evaluate, if knees in diseased states are more vulnerable to negative effects of increased intra-articular temperatures in sports.

\section{Competing interests}

In support of their research, one or more authors received grants or outside funding from Aircast, Inc., Summit, New Jersey, U.S.A. None of the authors received payments or other benefits or a commitment or agreement to provide such benefits from a commercial entity.

\section{Authors' contributions}

$\mathrm{CB}$ was responsible for the manuscript preparation, participated in the design and conception of the study and the data analysis. JS participated in the conception of the study, supervising the protocol and data analysis. SF participated in the conception of the study, supervising the protocol, data analysis and critically reviewing earlier versions of the manuscript. GC participated in the initial conception of the research question, supervising the protocol and provided the infrastructure for the jogging setting. HHP was responsible for the initial conception of the research question, supervising the protocol, securing funding and critically reviewing earlier versions of the manuscript. All authors read, edited, and approved the final version of the manuscript.

\section{Acknowledgements}

The authors wish to thank the staff of the "Lets People Move" Institute in Perugia, especially F. Vercillo, G. Zamarra and M. Lorenzini for their kind support and PD Dr. phil. S. Schneider for his assistance in performing the statistical analysis.

\section{References}

I. Horvath SM, Hollander JL: Intra-Articular Temperature as a Measure of Joint Reaction. J Clin Invest 1949, 28(3):469-473.

2. Martin SS, Spindler KP, Tarter JW, Detwiler K, Petersen HA: Cryotherapy: an effective modality for decreasing intraarticular temperature after knee arthroscopy. Am J Sports Med 200I, 29(3):288-29I.

3. Haimovici $\mathrm{N}$ : Three years experience in direct intraarticular temperature measurement. Prog Clin Biol Res 1982, 107:453-46I.
4. Ho SS, Coel MN, Kagawa R, Richardson AB: The effects of ice on blood flow and bone metabolism in knees. Am J Sports Med 1994, 22(4):537-540.

5. Louise Fincher A, William Woods G, O'Connor DP: Intraoperative Arthroscopic Cold Irrigation Solution Does Not Affect Postoperative Pain and Swelling. J Athl Train 2004, 39(I): 12-16.

6. Oosterveld FG, Rasker JJ: Effects of local heat and cold treatment on surface and articular temperature of arthritic knees. Arthritis Rheum 1994, 37(I I): I578-I582.

7. Sanchez-Inchausti G, Vaquero-Martin J, Vidal-Fernandez C: Effect of arthroscopy and continuous cryotherapy on the intra-articular temperature of the knee. Arthroscopy 2005, 2I(5):552-556.

8. Warren TA, McCarty EC, Richardson AL, Michener T, Spindler KP: Intra-articular knee temperature changes: ice versus cryotherapy device. Am J Sports Med 2004, 32(2):44I-445.

9. Cohn BT, Draeger RI, Jackson DW: The effects of cold therapy in the postoperative management of pain in patients undergoing anterior cruciate ligament reconstruction. Am J Sports Med 1989, 17(3):344-349.

10. Lessard LA, Scudds RA, Amendola A, Vaz MD: The efficacy of cryotherapy following arthroscopic knee surgery. J Orthop Sports Phys Ther 1997, 26(I): 14-22.

11. Levy AS, Marmar E: The role of cold compression dressings in the postoperative treatment of total knee arthroplasty. Clin Orthop Relat Res 1993:174-178.

12. Schroder D, Passler HH: Combination of cold and compression after knee surgery. A prospective randomized study. Knee Surg Sports Traumatol Arthrosc 1994, 2(3): 158-165.

13. Webb JM, Williams D, Ivory JP, Day S, Williamson DM: The use of cold compression dressings after total knee replacement: a randomized controlled trial. Orthopedics 1998, 2 I (I):59-6I.

14. Morsi E: Continuous-flow cold therapy after total knee arthroplasty. J Arthroplasty 2002, 17(6):718-722.

15. Barnes WS, Larson MR: Effects of localized hyper- and hypothermia on maximal isometric grip strength. Am J Phys Med 1985, 64(6):305-3।4.

16. Dover G, Powers ME: Cryotherapy does not impair shoulder joint position sense. Arch Phys Med Rehabil 2004, 85(8): I 24I-I 246.

17. Hopkins JT, Stencil R: Ankle cryotherapy facilitates soleus function. J Orthop Sports Phys Ther 2002, 32(12):622-627.

18. Hopper D, Whittington D, Davies J: Does ice immersion influence ankle joint position sense? Physiother Res Int 1997, 2(4):223-236.

19. Melnyk M, Faist M, Claes L, Friemert B: Therapeutic cooling: no effect on hamstring reflexes and knee stability. Med Sci Sports Exerc 2006, 38(7): 1329-1334.

20. Sanya $A O$, Bello AO: Effects of cold application on isometric strength and endurance of quadriceps femoris muscle. Afr J Med Med Sci 1999, 28(3-4): 195-198.

21. Uchio Y, Ochi M, Fujihara A, Adachi N, Iwasa J, Sakai Y: Cryotherapy influences joint laxity and position sense of the healthy knee joint. Arch Phys Med Rehabil 2003, 84(I): I 31 - 135.

22. Fitzgerald GK, Axe MJ, Snyder-Mackler L: A decision-making scheme for returning patients to high-level activity with nonoperative treatment after anterior cruciate ligament rupture. Knee Surg Sports Traumatol Arthrosc 2000, 8(2):76-82.

23. Noyes FR, Mooar PA, Matthews DS, Butler DL: The symptomatic anterior cruciate-deficient knee. Part I: the long-term functional disability in athletically active individuals. J Bone Joint Surg Am 1983, 65(2): 154-162.

24. Kim YH, Baek SS, Choi KS, Lee SG, Park SB: The effect of cold air application on intra-articular and skin temperatures in the knee. Yonsei Med J 2002, 43(5):62I-626.

25. Zaffagnini S, Allen AA, Suh JK, Fu FH: Temperature changes in the knee joint during arthroscopic surgery. Knee Surg Sports Traumatol Arthrosc 1996, 3(4): 199-201.

26. Zaffagnini S, lacono F, Petitto A, Loreti I, Fu FH, Marcacci M: Cryol Cuff use after arthroscopic surgery: effect on knee joint temperature. Am J Knee Surg 1998, I I (4):203-207.

27. Woolley DE, Evanson JM: Collagenase and its natural inhibitors in relation to the rheumatoid joint. Connect Tissue Res 1977, 5(I):3I-35.

28. Harris ED Jr., McCroskery PA: The influence of temperature and fibril stability on degradation of cartilage collagen by rheumatoid synovial collagenase. N Engl J Med I 974, 290(I): I-6. 
29. Oosterveld FG, Rasker JJ, Jacobs JW, Overmars HJ: The effect of local heat and cold therapy on the intraarticular and skin surface temperature of the knee. Arthritis Rheum 1992, 35(2):|46-|5|.

30. Oosterveld FG, Rasker JJ: Treating arthritis with locally applied heat or cold. Semin Arthritis Rheum 1994, 24(2):82-90.

31. Rubley MD, Denegar CR, Buckley WE, Newell KM: Cryotherapy, Sensation, and Isometric-Force Variability. J Athl Train 2003, 38(2): II3-II9.

32. Tremblay F, Estephan L, Legendre M, Sulpher S: Influence of Local Cooling on Proprioceptive Acuity in the Quadriceps Muscle. J Athl Train 200I, 36(2): I19-123.

33. Altman DG: Practical Statistics for Medical Research. London , Chapman \& Hall; 1990.

\section{Pre-publication history}

The pre-publication history for this paper can be accessed here:

http://www.biomedcentral.com/1471-2474/9/46/prepub

Publish with Biomed Central and every scientist can read your work free of charge

"BioMed Central will be the most significant development for disseminating the results of biomedical research in our lifetime. "

Sir Paul Nurse, Cancer Research UK

Your research papers will be:

- available free of charge to the entire biomedical community

- peer reviewed and published immediately upon acceptance

- cited in PubMed and archived on PubMed Central

- yours - you keep the copyright

Submit your manuscript here:

http://www.biomedcentral.com/info/publishing_adv.asp 